\title{
The Role of Computed Tomography in Blunt Abdominal Trauma
}

\author{
Om Bahadur Karki ${ }^{1}$ \\ 'Department of Surgery, Manipal College of Medical Sciences, Pokhara, Nepal.
}

Introduction: Blunt injury trauma is regularly encountered in the emergency department. Diagnostic tools that help in optimum management of blunt abdominal trauma include; Focussed Assessment Sonography for Trauma scan, Diagnostic peritoneal lavage and Computed Tomography scan. The aim of this study is to determine the validity of CT scan as an accurate diagnostic tool and its role in management of patients with blunt abdominal trauma.

Methods: A prospective analysis of 80 patients of blunt abdomen trauma who were admitted in Manipal Teaching Hospital, Pokhara, Nepal within a span of 15 months was done. Demographic data, mechanism of trauma, management and outcomes were studied. Organ injuries were graded using the Organ Injury Scale guidelines.

Results: Most of the patients in our study were in the age group of 21-40 years with an M: F ratio of 2.3:1. Road traffic accident $(47.5 \%)$ was the most common mechanism of injury. Spleen $(27.5 \%)$ was the commonest organ injured. CT scan was superior to FAST scan and had sensitivity of $97.3 \%$ specificity $75 \%$ positive predictive value $98.6 \%$. FAST scan had sensitivity of $78.9 \%$, specificity $50 \%$, positive predictive value $96 \%$ with p- value of $0.0034 .81 \%$ of patients were conservatively managed.

Conclusion: In conjunction with close clinical monitoring, CT scan is reliable in the evaluation and management of blunt abdominal trauma patients. Our study also shows CT as a superior diagnostic modality compared to FAST scan.

Keywords: blunt abdominal trauma; CT scan; FAST scan; road traffic accident.

\section{INTRODUCTION}

Trauma is the leading cause of death in persons under 45 years of age, with $10 \%$ of these fatalities attributable to abdominal injuries. ${ }^{1}$ Missed intra-abdominal injuries continue to cause preventable deaths. ${ }^{2}$ Blunt Abdominal Trauma usually results following road traffic accidents, assaults, recreational accidents, or falls. ${ }^{3}$ Clinical findings are compounded by factors like fractures of ribs, vertebrae and pelvis or other associated injuries. ${ }^{4}$ Major change in the paradigm of the management of blunt abdominal trauma is the introduction of nonoperative management coinciding with the availability of Computed Tomograpy (CT) scans, hence the role of imaging becomes even more paramount for the safe practice of such surgical restraint. ${ }^{5,6}$

CT scans, unlike direct peritoneal lavage (DPL) or Focused Assessment with Sonography for Trauma (FAST), have the capability to determine the source of

Correspondence: Dr. Om Bahadur Karki, Lecturer, Department of Surgery, Manipal, College of Medical Sciences, Pokhara, Nepal. Email: karkiom10@gmail.com, Phone: +977-9846080576. 
haemorrhage, defining the severity of solid organ injury, retroperitoneal injuries and genitourinary system. ${ }^{3,7}$ It is contraindicated in patients with clear indication of laparotomy and in haemodynamically unstable patients. ${ }^{8}$

The objective of the study was to assess the efficacy of CT scan as an accurate diagnostic tool in patients with blunt abdominal trauma and to suggest guidelines based on the above result

\section{METHODS}

This hospital based prospective study was conducted over a period of 15 months (December, 2014 to February,2016) in the department of Surgery, Manipal Teaching Hospital, Pokhara, Nepal. Ethical clearance was obtained from the Institutional Research Committee prior to the study and informed consent taken from patient or their guardian. Eighty patients of all ages and sex presenting with blunt injury abdomen were included in the study. Indications for admission were either the detection of a significant abdominal injury requiring treatment or a suspicion of such an injury and need for further investigation or followup. Patients were resuscitated and preliminary FAST scan examination performed, patients selected fit for abdominal CT were then scanned. Patients who had at least one of these scans interpreted as positive, were included in the study. CT scan of abdomen and pelvis was done in patients with clinical suspicion of intra-abdominal injury, polytrauma patients and with a positive ultrasonography study.

Contrast enhanced CT was performed with $50 \mathrm{ml}$ of intravenous iodinated contrast, $5-10 \mathrm{~mm}$ thick slices were taken from domes of diaphragm to the pubic symphysis with additional thin slice sections taken where ever required. Early and five minutes delay were taken in cases of renal injuries. Oral contrast was avoided since blunt injury abdomen patients were potential candidates for emergency surgery and hence general anesthesia. Diagnostic peritoneal lavage was not performed in any of the patients. The exclusion criteria was as follows:

1. Penetrating abdominal injury

2. Patients with normal FAST scan and CT scans

3. Blunt injury abdomen patients where CT scan was not done

4. Contraindication for CECT imaging like hypersensitivity to contrast media, increased serum creatinine, pregnancy.

5. Patients who refused admission

6. Patients who were referred to other centre for further management.
Individual organ injuries were graded according to the OIS system. FAST scan and CT scan reports were compared with operative findings in operated cases and in those cases where CT was positive and surgery deferred, clinical follow up was the yardstick.

Data were entered in Microsoft excel and statistical analysis done using SPSS-16.

\section{RESULTS}

Eighty patients with blunt injury abdomen were prospectively studied, 56 (70\%) were male and $24(30 \%)$ female. Their ages ranged from 3 to 68 years (mean $30.86 \pm 19.70$ years). Road traffic accident was the commonest mode of injury and it was the cause of abdominal trauma in 38(47.5\%) patients. In 32(40\%) patients, the injury was caused due to fall from height. Spleen $(27.5 \%)$ was the commonest organ to be injured followed up by liver (20\%), Kidney (11.2\%), mesentry $(8.75 \%)$ and bowel $(7.5 \%)$ (Figure 1$)$. Chest injuries including rib fractures, pneumo/hemothorax, lung contusion besides fracture of pelvis and spine were other injuries commonly associated with abdomen trauma scan in our study. These injuries were detected by CT scan rather than FAST scan.

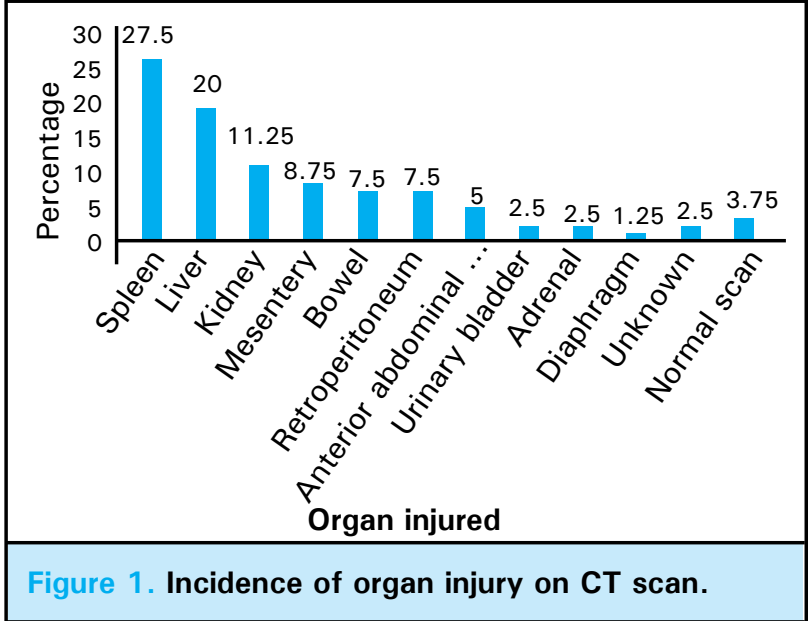

Out of 47 patients of solid organ injury diagnosed and graded by CT-OIS grading, only five underwent surgery, others could be managed conservatively. Those who underwent surgery were of CT-OIS grade IV or higher. (Table 1). The sensitivity and specificity of CT scan and FAST were as follows. (Table 2 and Table 3).Table 2 shows the Sensitivity of $97.3 \%$, Specificity

of $75 \%$, Positive predictive value of $98.6 \%$, Negative predictive value of $60 \%$. Similarly Table 3 shows Sensitivity of $78.9 \%$, Specificity of $50 \%$, Positive predictive value of $96 \%$ and Negative predictive value of $11 \%$. 


\begin{tabular}{|c|c|c|c|}
\hline \multicolumn{4}{|c|}{$\begin{array}{c}\text { Table 1. CT-OIS grading and management in patients } \\
\text { with solid organ injury }(\mathbf{n}=47) .\end{array}$} \\
\hline $\begin{array}{c}\text { OIS } \\
\text { grade }\end{array}$ & $\begin{array}{c}\text { Total } \\
\text { number of } \\
\text { patients }\end{array}$ & $\begin{array}{c}\text { No. of } \\
\text { Conservatively } \\
\text { managed patients }\end{array}$ & $\begin{array}{c}\text { No. of } \\
\text { operated } \\
\text { patients }\end{array}$ \\
\hline I & 2 & 2 & \\
II & 10 & 10 & \\
III & 19 & 19 & 4 \\
IV & 15 & 11 & 1 \\
V & 1 & & \\
\hline
\end{tabular}

Table 2. Sensitivity and specificity of CT scan in blunt injury abdomen.

\begin{tabular}{|llll|}
\hline & $\begin{array}{l}\text { Patients } \\
\text { with positive } \\
\text { finding }\end{array}$ & $\begin{array}{l}\text { Patients } \\
\text { without } \\
\text { positive } \\
\text { findings }\end{array}$ & \\
$\begin{array}{l}\text { CECT } \\
\text { abdomen } \\
\text { positive }\end{array}$ & 74 & 1 & 75 \\
$\begin{array}{l}\text { CECT } \\
\text { abdomen }\end{array}$ & 2 & 3 & 5 \\
negative & 76 & 4 & \\
\hline
\end{tabular}

Table 3. Sensitivity and specificity of USG in blunt injury abdomen.

\begin{tabular}{|llll|}
\hline & $\begin{array}{l}\text { Patients } \\
\text { with positive } \\
\text { finding }\end{array}$ & $\begin{array}{l}\text { Patients without } \\
\text { positive findings }\end{array}$ & \\
$\begin{array}{l}\text { FAST scan } \\
\text { positive }\end{array}$ & 60 & 2 & 62 \\
$\begin{array}{l}\text { FAST scan } \\
\text { negative }\end{array}$ & 16 & 2 & 18 \\
& 76 & 4 & \\
\hline
\end{tabular}

In the present study, CT scan had detected additional injuries in $18.7 \%$ patients (15 out of 80 ), which were missed by FAST. The significance between CECT and FAST in detection of intra-abdominal injury in our series is shown in table 6. P-value of 0.0034 was observed, so the test was significant. (Table 4) Mortality rate in our study was $5 \%$.

Table 4. Comparision of CT scan with FAST scan in blunt injury abdomen.

\begin{tabular}{|lll|}
\hline & $\begin{array}{l}\text { Patients without } \\
\text { significant } \\
\text { finding }\end{array}$ & $\begin{array}{l}\text { Patients with } \\
\text { positive findings }\end{array}$ \\
$\begin{array}{l}\text { CECT abdomen } \\
\text { and pelvis }\end{array}$ & 5 & 75 \\
FAST scan & 18 & 62 \\
\hline
\end{tabular}

\section{DISCUSSION}

The mean age of patients was 30.86 years. No age group is exempted from traumatic injury of abdomen, but that it is more common in the second to fourth decade of life because this age represent working population. A similar incidence was reported by Vadodariya et $\mathrm{al}^{3}$ and Mohapatra et al. ${ }^{9}$ Majority of our patients were male (Male: female $=2.3: 1$ ). The incidence of abdominal trauma in male population is higher because in our country males lead more active life and have more outdoor activities. Road traffic accident is the commonest mode of injury in blunt injury abdomen. This is consistent with the studies of Kumar et al, ${ }^{1}$ Radwan et $\mathrm{al}^{4}{ }^{4}$ and Mohapatra et al. ${ }^{8}$ Other causes are fall injuries, physical assult. We also had some cases of blunt injury abdomen due to earthquake related injuries as Nepal suffered from 7.8 magnitute earthquake in the month of April, 2015. Spleen was the most common organ to be injured followed up by liver, kidney, mesentry, bowel etc. Studies in India by Vadodariya et $\mathrm{al}^{3}{ }^{3}$ in Jordan by Hamidi et al. ${ }^{2}$ also showed spleen as the commonest organ to be injured in blunt injury abdomen. Chest injuries, fracture of pelvis and spine were the maximum associated injuries.

FAST scan was the preliminary investigation and was followed by CT scan in our patients. CT scan had a sensitivity of $97 \%$, specificity of $75 \%$ and a positive predictive value of 98.60 while FAST had sensitivity of $78.9 \%$, specificity of $50 \%$ and a positive predictive value of $96 \%$. CT scan had detected additional injuries in $18.7 \%$ patients, which were missed by USG. Chi square: $8.581 \mathrm{P}$ value $=0.0034(<0.05)$ So the test is highly significant and it indicates that CT scan is better investigation as compared to USG abdomen in cases of blunt abdominal trauma. Studies by Hamidi et al, ${ }^{2}$ Mallik K et al. ${ }^{7}$ also demonstrates the superiority of CT over FAST. CT scan is helpful in detecting other associated injuries like fracture of spine and pelvis. Many retroperitoneal injuries go unnoticed with DPL and FAST examinations. Poor results of FAST scan may be due to overlying bowel shadow, surgical emphysema, empty bladder and lack of skilled radiologist at emergency hours. FAST can be a valuable initial investigation; however, FAST can miss crucial injuries and may lead to inappropriate management in some patients. Five patients incorrectly diagnosed by CT scan were of bowel injury or mesentry injury. Atri et al showed that sensitivity of the three observers in diagnoses of surgically important bowel or mesenteric injury by CT scan ranged from $87 \%-95 \% .^{10}$

The possibility of surgical management increases with higher OIS grading of solid organ injury, however OIS grading in isolation appears inadequate for predicting 
management protocol. Hence correct management of blunt abdominal trauma should be based on clinical examination, hemodynamic stability of patient in conjunction to radiological investigations.

Limitations of the study was small sample size and FAST scan being performed by residents rather than consultants.

\section{CONCLUSION}

This study shows that CT scan is a superior diagnostic modality in the diagnosis and management of blunt abdominal trauma. USG can be a valuable initial investigation. OIS grading, quantification of hemoperitoneum, clinical stability of patient and anatomical site of organ injury predict the management protocols in the majority of the patients.

\section{ACKNOWLEDGEMENT}

Staffs, nurses, residents and doctors of department of Surgery and department of Radiology Manipal Teaching Hospital, Pokhara, Nepal.

\section{REFERENCES}

1. Kumar MM, Venkataramanappa M, Venkataratnam I, Kumar NV, Babji K. Prospective evaluation of blunt abdominal trauma by computed tomography. Indian J Radiol Imaging 2005;15:167-73

2. Hamidi MI, Aldaoud KM, Qtaish I. The Role of Computed Tomography in Blunt Abdominal Trauma. Sultan Qaboos Univ Med J 2007;7(1): 41-6.

3. Vadodariya KD, Hathila VP, Doshi SM. The role of Computed Tomography in blunt abdominal trauma as investigative tool conducted at tertiary level hospital, Vadodara. Int J Med Sci Public Health 2014;3:433-435.

4. Radwan MM, Abu-Zidan FM. Focussed Assessment Sonograph Trauma (FAST) and CT scan in blunt abdominal trauma: surgeon's perspective. Afr Health Sci. 2006;6(3):187-190.

5. Velmahos G, Toutouzas K, Radin, et al. High success with nonoperative management of blunt hepatic trauma: the liver is a sturdy organ. Archives of Surgery. 2003; 138(5): 475-480.
6. Wu S-C, Chow K-C, Lee K-H, Tung C-C, Yang A, Lo C-J. Early selective angioembolization improves success of nonoperative management of blunt splenic injury. American Journal of Surgery. 2007; 73(9): 897-902.

7. Mallik K, Vashisht S, Thakur S, Srivastava DN. Comparative evaluation of ultrasonography and $\mathrm{CT}$ in patients with abdominal trauma: A prospective study. Indian J Radiol Imaging. 2000;10(4):237-43.

8. M Magray, M Shahdhar, M Wani, M Shafi, J Sheikh, H Wani. Studying The Role Of Computed Tomography In Selective Management Of Blunt Abdominal Trauma Patients In A Single Tertiary Care Centre In Northern India. The Internet Journal of Surgery. 2013;30(2)

9. Mohapatra S, Pattanayak SP, Rao KRRM, Bastia B: Options in management of solid visceral injuries from blunt abdominal trauma. Indian J Surg; 2003; 65: 263-268

10. Atri M, Hanson JM, Grinblat L, Brofman N, Chugtai T, Tomlinson G: Surgically important bowel and/or mesenteric injury in blunt trauma: accuracy of multidetector CT for evaluation. Radiology 2008, 249(2):524-33. 